\title{
e-Calculus at IZTECH ${ }^{\star}$
}

\author{
Ünal Ufuktepe, Günnur Ufuktepe, Asli Deniz, and Veli Dündar \\ Izmir Institute of Technology, Izmir, Turkey \\ unalufuktepe@iyte.edu.tr
}

\begin{abstract}
In today's new economy, characterized by industrial revolutions, globalization and information technology changes traditional classroom and teaching methods. Calculus is the basic course for the fresher at university. Mathematics has a negative development at universities and colleges. The number of students taking mathematics courses and those successfully passing the exams are rapidly decreasing. To overturn this negative development, it may be necessary to teach in a different way. This is where new technology could play an important role. We create a web browser environment by using the webMathematica, which is a new technology based on Java Server Page, Tomcat and Mathematica, in learning calculus. The modules consist of topic modules linked with case study modules, to help learn calculus and see it in context. The aim of our project is to use new technology to present mathematics on the web, and create a pilot course for students and teachers available free on the web. The heart of our approach is the development of mathematical power: understanding, using, and appreciating mathematics. Students can reach any documents for calculus and solve their problems with webMathemat$i c a$ to check whether their results are correct or not. It is possible to reach our page at the following URL address: http://galois.iyte.edu.tr/calculus
\end{abstract}

\section{Introduction}

Learning is the most indispensable activity in the current knowledge-based new economy, characterized by globalization, rapid changes in information technology, increased intensive competition and industrial revolutions. Education becomes a huge business sector in the global world. It is estimated that education and training from pre-school to retirement is 2 trillion USD marketplace 12 .

Because of the increased use of networked computers and the achievement of telecommunication technology, the internet has been widely recognized. The concepts of traditional education do not fit well with the new world of life-long learning. The traditional context of learning models is being changed radically. Roles of instructor, learners and curriculum have been changing rapidly. People usually have changes in their career and businesses as life turns into nonlinear and chaotic structure from linear form.

Traditional classrooms are inefficient for learning and teaching activities. Teaching methods need to be more portable and flexible. When all these are

\footnotetext{
* Supported in part by ONR under contracts N00014-01-1-0796 and N00014-01-1-0708, NSF under grant CCR-0305387, and a gift from Microsoft Research.
} 
taken into consideration, importance of e-learning is further underlined. There are a variety of definitions of e-learning. In this study e-learning refers to any type of a learning situation when instructional content is delivered electronically via the internet, when and where people need it.

It is estimated that $50 \%$ of all employees' skills become outdated within 3-5 years. As a necessity of rivalry in the business sector, there is great competition between companies. In 1999, the companies in the USA spent 62.5 billion dollars on training and educating their employees 12. For companies, one of the basic criteria for demanded education courses, is to have efficient and productive education methods. Many companies prefer e-learning in order to decrease cost and increase efficiency for these education activities. The market for web-based corporate learning in the USA is expected to reach 11.4 billion by 2003, up from 550 million in 1998 [11.

In academics, e-learning has supported significant improvement in interactivity, collaboration and delivery of online education. Many universities are now equipped with computer labs. In recent years there has been research examining university students 'academic involvement' and approaches to e-learning at a few universities in Turkey. E-learning in universities in Turkey is still in the early state. There are many theoretical and technological issues that need to be explored. The new focus of distance learning is to build a cost-effective learning infrastructure that enables anytime, anywhere, self-paced and interactive learning. Our study has been planned as an electronic platform in order to support the studies of students in classrooms and answer questions 24 hours a day and also help students who take the same course in different universities.

The traditional face to face education has advantages from the fact that the student and instructor get closer, relaxed and comfortable but restriction of course duration, lack of qualified specialists and many teenagers expand the cost of education. Due to these reasons face to face education is a deterrent at the same time.

It can be difficult to carry on the attention of students when using a lot of learning materials in a classroom. Moreover, the traditional education is instructor-centric and everything (tools, materials, discussions, topics, integrity) is under the instructor's control. At present, learning is shifting from instructorcentric to learner-centric, which emphasizes relevance personalization (learning according to individual interests, previous knowledge and style, etc.) and learning flexibility (time and location). The education by exposition has been replaced with learning according to demands or learning by interrogation and experiments.

E-learning is a revolution for education. E-learning is not a system that is preferred to classical classroom, it is just a complement for face to face and distance education. E-learning provides the knowledge which has been prepared by experts. Today, thousands of courses of degree and certificate programs are presented by universities worldwide via the internet. For example, there are more than 30,000 students who benefit from e-learning platform in Phoenix University in USA. 
Some programs are based on e-learning with computer entirely, whereas some of them are directed only for a limited number of online courses. Due to these reasons, some technical and theoretical points should be analyzed at the beginning of application of e-learning at universities.

E-learning can be either synchronous or asynchronous. Synchronous e-learning requires simultaneous participation of all learners and instructors at different locations. It can also be considered as scheduled delivery of learning. Asynchronous e-learning does not require simultaneous participation of learners and instructors. People can learn at any time. Therefore, asynchronous e-learning is "on-demand delivery" of learning, which over the learning process and content. Our study is based on asynchronous e-learning.

Many researches have been conducted on e-learning. Highlights of several important benefits of e-learning are as follows [10/3.54413:

1) Flexibility of time and location: e-learning eliminates the barriers of time and distance.

2) Cost and time saving

3) Self-paced and just-for-me learning: E-learning provides activities by which learners can learn of their own capacity. Each student choose his own learning activity according to his/her own skills, background, attention and status. Researches indicate that e-learning guides the efficient traditional education which student actively participates. 34.

4) Collaborative Learning Environment: E-learning is a resource that enables learners to interact with each other despite they are not in the same location at the same time. The system of learning on the electronic platform encourages learners ask questions. At this point, learners bring up their own vision confidently and share their ideas and opinions with the others eagerly.

5) Independent Communication Platform for Students: Students can get help from instructors through the internet. Therefore they are provided with communication tool that are not usually available in traditional classroom 1013 .

6) Unlimited use of learning materials : Students allow unlimited access and retrieval of electronic learning materials. In this atmosphere the instructor's patience is endless.

\section{Web-Mathematica and E-Learning}

web-Mathematica is a use of Mathematica on web platform. The basic reason of using mathematica on the web platform is the fact that Mathematica has a large scale of applications about calculation. Web technology are making progress in many areas. Mathematica is an irreplaceable software which is used in many areas of science. Mathematica is a powerful software in terms of data analysis, animations related with function graphs, variety of probability operations, practices about physics, chemistry, biology, engineering and image processing. Mathematica provides a view on a huge opportunity. It is suitable for every kinds of calculation operations. 
Web is consist of a lot of server programs. These programs respond the user's demands. Demands are sent from demander computers which are used frequently by learners who want to collect information from the server. There are comprehensive programs which support HTTP like connection to other tools and data bases. Demander software is generally a web scanner. It is required to provide some dynamic technologies for existence of web site which support interactive calculations. This can be supported by server or demander as well.

Schools, universities and the other education associations can present interactive dynamic lectures on their own sites by using web-Mathematica. Therefore, students have opportunity to write their own examples and see the results. Besides, they can have exams on the internet platform with demanded levels and see the results of exams after studies on the site 1918.

\section{Applications of E-Calculus}

At Izmir Institute of Technology (here after IZTECH) all science, engineering and architecture students take calculus courses for two terms at the first year is obligatory. Due to differences of students' backgrounds, problems derived from the current general exam for the universities, ratio of success has never passed $50 \%$ at total. We began with the idea of creating lectures in the web platform for computer and mechanical engineering students. We decided to let students design the web page first . The present site has three main objectives:

1) Students can find out all announcements about the course (date of exams, exam contents, questions with rewards, etc.). They can download the lecture notes, sample exams and projects.

2) To apply questionnaire on the performance evaluation of the instructor according to weekly progress.

3) To create a discussion form about the web site and the course .

At the beginning, the page was constructed by students. It is moved to the institute's address at the end of fall term.

This learning activity has improved the traditional calculus classroom. The students expressed that this application had contributed very much to the understanding of the course at the end of the spring term. It was observed that some students preferred the lecture notes which were presented on web platform to taking notes in classrooms and participation in classroom become more active and student orientated.

This study indicated that the students who are passive and shy in the traditional classroom education are treated independently and adapted to the classroom easily after some time.

We compared face to face education with distance education in different areas pedagogically. We have established that difference in the students motivation was ignorable. Success of some student's indicated that online education may be better than classroom education in some cases 16 21. 
It was seen that e-learning has provided students to acquainted with technology and to get skill about technological knowledge after comparing the studies 16. At this point IZTECH students strengthened their skills and they realized the role of the internet for education and researches. We enabled the students to interact strongly with mathematics and know about e-learning with this ecalculus study. Although students use internet very often for project studies of which has the ratio $20 \%$ to total when the sources in the internet are insufficient, they use libraries frequently.

In multiple sensual platforms it is possible students develop their skills and increase the level of information [15]. Applications of e-calculus is broaden. In one hour of the calculus course (five hours a week), students studied with Mathematica 5.0 software in mathematics labs which are equipped with computers and the internet connection under specialists' controls.

They had taken projects at the beginning of the term, carried on with the task as groups which were consist of two or three students and presented them to the whole academy in the form of a seminar and shared their experience and findings with their friends. Researches indicate that the multimedia-based teaching is effective on students' performance in individual problem solving skills and increased the duration of students' attention [1/714/24 20].

Calculus course which exhibited with techniques of visual exposition and theoretical approach by using the advantages of latest changes in information technologies in the created web page. The lecture become interactive on the internet platform by integrating animations of limits, derivatives and integrals of functions with multimedia effects. When a student struggles with given homework problems and he/she has difficulty, he/she could compare the results he/she achieved with the ones available on the web site. Thanks to the animations, it is facilitated students' perception by visualizing abstract concepts.

\section{Conclusion}

Technology can provide mechanisms to sustain assistance to mathematics teachers in their use of technology to implement mathematics education reforms in their classes. Technology enables mathematics education reform, but it is not reform per se. We must provide mathematics teachers extended opportunities to experience and do mathematics in an environment supported by diverse technologies.

The power of information technology depends on including and interpreting variety of information which people need in order to learn and make decisions easily. The information management involves collecting, arranging and sharing of information. In e-learning, it is sufficient that collecting and arranging information and making them proper and updating in order to be used it again.

The web site provides a unique method that provides a mechanism for creating a community of learners who recognize each other as powerful resources in the teaching-learning endeavor; serves as a vehicle for delivery of continuous instruction related to content, pedagogy, assessment and use of the technology 
itself; provide tools which can be accessed any-time, any-where and allows for instantaneous updating promoting continual renewal opportunities for all members of the learning community; serve as a source of annotated linkages to other exemplary web sites and to other databases which can, in turn, promote collaborative project-based learning using real-time data.

The site that we considered is based on student centered model which teacher guides. As a reason of the fact that this page is used by students from the other universities, instructors and specialists are taken on updating the page.

There are currently variety of e-learning systems today. We tried to get face to face education and e-learning together and make interactive. Although e-learning has wide interaction area and broad social potential, it has some problems. We could not over come some problems in our experimental study. They are ordered above:

1. Materials based on text: In e-calculus, also there are materials which are based on only texts. These could not attract users. Some of students preferred notes which were taken in classrooms.

2. Problem of reaching the internet: As a Result of non-availability of internet connection outside the institute created problems for some students.

3. Minor ratio of interaction and user flexibility: In traditional classrooms, students and teachers keep in interaction physically which is not exist for elearning platform. Questions could not be answered about abstract concepts one to one. As a reason of lack of specialists, texts could not become interactive at expected level.

4. E-tests could not be applicable and questions with rewards could not be updated often.

The affirmative changes which are observed in e-calculus application are ordered above:

1) Communication become very fast for lectures which are twice a week. The student who do not have internet connection were informed of announcement and dates of exams from their friends or at the internet cafes. Questions with rewards provided students to establish dialogue with other instructors and use other academic platforms.

2) The conductivities in classrooms of instructors who give the course was seen particularly in weekly polls.

3) It was observed that the amount of visitors for the site increased in weeks before and after exam terms.

4) It is seen that the past project samples in the site were downloaded most.

5) It is observed when a question with reward become a part of exam, attention increased.

6) Students expressed their opinion, ideas and observation about instructors briefly, whereas they could not do so even at students' polls.

7) It was noticed that the ratio of the successful students who had e-calculus applications is $20 \%-25 \%$ more then the departments who did not have. 
The heart of our approach is the development of mathematical power: understanding, using, and appreciating mathematics. We try to model and explore collaborative instructional strategies. We believe that if this study transforms into online lecture in a project, it will have benefits to the productivity of the students who use distance education.

\section{References}

1. Agius HW, Angelides MC. Developing knowledge-based intelligent multimedia tutoring systems using semantic content-based modeling. Artificial Intelligence Review 1999;13:55-83

2. Alavi M. Computer-mediated collaborative learning: An empirical evaluation. MIS Quarterly 1994:159-174.

3. Beam P, Cameron B. "But what did we learn ...?": Evaluating online learning as process. In: Proceedings on the Sixteenth Annual International Conference on Computer Documentation, Sept. 24-26, 1998, Quebec, Canada, 258-264.

4. Burgstahler S. Teaching on the Net: What's the difference? T.H.E. Journal 1997;24(9):61-64.

5. Carswell L. Teaching via the Internet: The impact of the Internet as a communication medium on distance learning introductory computing students. In: Proceedings of the Conference on Integrating Technology into Computer Science Education, June 1-5, 1997, Uppsala, Sweden, 1-5.

6. Carswell L. The 'Virtual University': Toward an Internet paradigm? In: Proceedings of 6th Annual Conference on the Teaching of Computing/3rd Annual Conference on Integrating Technology into Computer Science Education on Changing the Delivery of Computer Science Education, 1998.

7. Corbett AT, Anderson JR. Knowledge decomposition and subgoal reification in the ACT programming tutor. In: Proceedings of Powering E-Learning In the New Millennium 217 AI-ED 95: 7th World Conference on Artificial Intelligence in Education, 1995.

8. Hiltz SR. Teaching in a virtual classroom. In: Proceedings of International Conference on Computer Assisted Instruction (ICCAI'95), March 7-10, 1995, at Hsinchu, Taiwan.

9. Hiltz SR, Benbunan-Fich R. Supporting collaborative learning in asynchronous learning networks: Software engineering or symbolic interactionism [online]. Invited Keynote Address for the UNESCO/ Open University Symposium on Virtual Learning Environments and the Role of the Teacher, Milton Keynes, England, April 28, 1997. Available: http://eies.njit.edu/ hiltz.

10. Hiltz SR, Wellman B. Asynchronous learning networks as a virtual classroom. Communications of the ACM 1997;40(9):44-49. Available: ACM digital library.

11. Kerry B, Isakson J. The power of the Internet for learning: Moving from promise to practice. Report of the Web-Based Education Commission to the President and the Congress of the United States, Available: www.ed.gov/offices/AC/WBEC/FinalReport/WBECReport.pdf, 2000.

12. Khirallah DR. A new way to learn. Informationweek 22-23. Available: http://www.informationweek.com, 2000.

13. McCloskey DW, Antonucci YL, Schug J. Web-based vs. traditional course development: Identifying differences in user characteristics and performance outcomes. In: Proceedings of the International Business Schools Computing Association Annual Conference. Denver, Colorado, 1998. 
14. Senn JA. Capitalising on interactive multimedia technologies in dynamic environments [online]. 1997. Available: http://crm.hct.ac.ae/021senn.html.

15. Syed MR. Diminishing the distance in distance education. IEEE Multimedia JulySept., 2001:18-21.

16. Thompson M. Distance delivery of graduate-level teacher education: Beyond parity claims. Journal of Continuing Higher Education 1996;44(3):29-34.

17. Ubell R. Engineers turn to e-Learning. IEEE Spectrum 2000;59-63. USDLA (The United States Distance Learning Association). Research information and statistics [online]. Available: http://www.usdla.org/.

18. Ufuktepe Ü., Mathematics Courses with Mathematica at IZTECH, Proceeding of the fourth International Mathematica Symposium, Tokyo Denki University, Chipa, Japan, p. 493-498, 2001.

19. Ufuktepe Ü., Abdul Karim M.F., Pedagogical Issieus in webMathematica Applications in Distance Education, The Mathematics Education into the 21 st Century Project Procceding, Terrasini, Palermo, Italy, p.25-29 2002.

20. Weston TJ, Barker L. Designing, implementing, and evaluatingWebbased learning modules for university students. Educational Technology 2001;41(4):15-22.

21. Zhang D. Media structuration-Towards an integrated approach to interactive multimedia-based E-Learning. Ph.D. dissertation. The University of Arizona, 2002.

22. Zhang D, Nunamaker JF. A multimedia-enabled system for interactive self-paced learning. In: Proceedings of IASTED International Conference on Internet and Multimedia Systems and Applications, Nov. 19-23, 2000, at Las Vegas, Nevada, USA.

23. Zhang D, Zhao JL, Nunamaker JF. Media structuration theory: Towards a framework for effective multimedia-based e-Learning, 2002. Submitted to MIS Quarterly.

24. Zhang W. Chapter 8: Multimedia, technology, education and learning. Technological Innovations in Literacy and Social Studies Education [online], 1995. Available: http://tiger.coe.missouri.edu/ sslit95/. 